\section{LAS RUEDAS DE LARMAHUE: UNA MANIFESTACIÓN DE CONSTRUCCIÓN DE TERRITORIO Y PAISAJE AGRARI0'}

Jorge Larenas ${ }^{2}$, Antonio Sahady ${ }^{3}$, Marcelo Bravo ${ }^{4}$, Carolina Quilodrán ${ }^{5}$, Xenia Fuster ${ }^{6}$

\section{Resumen}

Puesto a prueba desde tiempos inmemoriales, el ingenio humano ha creado verdaderas obras de arte para dar respuesta a condiciones adversas. Una demostración de ello son las azudas o ruedas de agua, fruto de la necesidad de conseguir un eficiente riego de los campos destinados al cultivo. Otras culturas han enriquecido su diseño y perfeccionado su funcionamiento. Y en pleno valle central chileno -región de O'Higgins- se puede admirar, hoy en día, las azudas de Larmahue, como un objetivo articulador de diversas dinámicas políticas, sociales y económicas en el territorio, influyendo en su paisaje construido, cultural y patrimonial.

\section{THE WATERWHEELS OF LARMAHUE: AN EXPRESSION OF THE CONSTRUCTION OF TERRITORY AND AGRICULTURAL LANDSCAPE'}

Jorge Larenas ${ }^{2}$, Antonio Sahady ${ }^{3}$, Marcelo Bravo ${ }^{4}$, Carolina Quilodrán ${ }^{5}$, Xenia Fuster ${ }^{6}$

\begin{abstract}
Tested since time immemorial, human ingenuity has created true masterpieces in response to unfavorable conditions. Waterwheels are proof of this, as they were invented out of the need to provide efficient irrigation of farmlands. Other cultures have enhanced their design and perfected their operation. Located at the heart of the Chilean central valley in theO'Higgins Region the waterwheels of Larmahue emerge as an objective articulator that link different political, social and economic dynamics, thereby influencing the constructed, cultural and heritage landscape.
\end{abstract}


Sin embargo, estas ruedas de agua han debido padecer los inevitables desastres naturales y -lo que es injustificable-, los daños antrópicos traducidos en incuria y abandono. Los perjuicios en el patrimonio material se extienden, forzosamente, hacia la dimensión intangible y, de paso, hasta el paisaje natural. No es extraño que los recursos para recuperar estos bienes sean siempre escasos. De allí la necesidad de encontrar soluciones orientadas a la puesta en valor para su recuperación y posterior conservación de este reconocido patrimonio de origen ancestral

\section{PALABRAS CLAVE: GEOGRAFÍA CULTURAL, IDENTIDAD CAMPESINA, PAISAJE CULTURAL, PATRIMONIO CULTURAL \& RUEDAS DE AGUA.}

Fecha de recepción: 09.07.13

Fecha de aceptación: 29.08.14

1 El presente artículo es resultado del Proyecto FONDECYT N NI260 1120114, “Vigencia y Proyecciones de un Sistema de Regadío de Origen Ancestral: Las Azudas de Larmahue, en la Sexta Región de Chile" (2012-2013)

2 Chile. Licenciado y Magíster en Sociología. Académico y Director del Instituto de la Vivienda, Facultad de Arquitectura y Urbanismo Universidad de Chile. Correo electrónico: jlarenas@ uchilefau.cl

3 Chile. Académico del Instituto de Historia y Patrimonio, Facultad de Arquitectura y Urbanismo Universidad de Chile. Correo electrónico: asahady@uchilefau.cl

4 Chile. Académico Instituto de Historia y Patrimonio, Facultad de Arquitectura y Urbanismo Universidad de Chile. Correo electrónico:mbravo@uchilefau.cl

5 Chile. Académica Instituto de Historia y Patrimonio, Facultad de Arquitectura y Urbanismo Universidad de Chile. Correo electrónico: cquilodran@uchilefau.cl

6 Chile. Magister (C) en Hábitat Residencial y asistente de investigación en Instituto de la Vivienda, Facultad de Arquitectura y Urbanismo Universidad de Chile. Correo electrónico: xeniaff@ uchilefau.cl

190 revista invi № 82 / Noviembre 2014 / Volumen № 29: 189-216
However, these waterwheels have suffered the unavoidable effects of natural disasters and unjustified human-induced damage reflected by negligence and abandonment. This material damage inevitably extends towards an intangible dimension and passes to the natural landscape. It is no surprise then the lack of resources allocated for the restoration of these structures. Hence there is a need to find solutions oriented towards the recovery and conservation of this ancient and recognized piece of heritage.

\section{KEYWORDS: CULTURAL GEOGRAPHY, RURAL IDENTITY, CULTURAL LANDSCAPE, CULTURAL HERITAGE, WATERWHEELS.}

\author{
Received: 09.07.13
}

Accepted: 29.08.14

1 This paper is part of the FONDECYT Project $n^{\circ} 2601120114$, "Validity and Projection of an Ancient Irrigation System: the Waterwheels of Larmahue, Located in the Sixth Region of Chile" (2012-2013)

2 Chile. BA and MSc in Sociology. Director, the Housing Institute, Faculty of Architecture and Urban Development at the University of Chile.Email: jlarenas@uchilefau.cl

3 Chile. Academic, Institute of History and Heritage, Faculty of Architecture and Urban Development at the University of Chile. Email: asahady@uchilefau.cl

4 Chile. Academic, Institute of History and Heritage, Faculty of Architecture and Urban Development at the University of Chile. Email:mbravo@uchilefau.cl

5 Chile. Academic, Institute of History and Heritage, Faculty of Architecture and Urban Development at the University of Chile. Email: cquilodran@uchilefau.cl

6 Chile. MSC (c) in Residential Habitat and research assistant at the Housing Institute, Faculty of Architecture and Urban Develo pment at the University of Chile. Email: xeniaff@uchilefau.c 


\section{Introducción}

El presente artículo de reflexión se centra en el impacto territorial y paisajístico de la ancestral técnica de las azudas, en la localidad de Larmahue de la región de O'Higgins, la cual nació al amparo de la necesidad de enfrentar un uso eficiente del recurso hídrico, para regar los fértiles campos del Valle Central. Esta manifestación fue el atisbo de un proceso de organización y trabajo de los habitantes, que vieron en las ruedas giratorias la solución precisa para obtener el riego con aguas del río Cachapoal, el capital más valioso del área. Se ignora cómo tan singulares artilugios, de germen ancestral, llegaron a instalarse hace ya más de 70 años en este asentamiento rural. Sus bondades prácticas como sistema de riego así como sus cualidades paisajísticas han provocado su reproducción, con algunas variantes, en otras localidades próximas, tanto en el interior como fuera de la comuna de Pichidegua.

Los cultivos aledaños al curso del agua fueron favorecidos por la acción benefactora de las azudas, toda vez que permiten, en la actualidad, el riego de chacras, campos y viñedos que ponen en valor el paisaje rural. Su lógica constructiva y su respetuosa asimilación con el escenario campestre le otorgan valores intrínsecos que hablan de una vigorosa tradición cultural, cualidades que indujeron el reconocimiento nacional: las azudas fueran declaradas
Monumento Histórico en 1998. No obstante, la nula conservación que se les ofrece las expone a su desaparición: en el año 2002 fueron incluidas en la Lista del Patrimonio Mundial en Peligro de Extinción según la organización World Monuments Watch. Como si no bastara con la erosión que les provoca el paso del tiempo, el terremoto de febrero del año 2010 produjo un gran daño no solamente en las estructuras de las ruedas, sino también en el paisaje cultural que sustenta la existencia de ellas y, por irradiación, en la calidad de vida de los habitantes.

Con todos estos antecedentes, surge un importante interés en comprender cómo estos artilugios son parte de un paisaje agrario construido y cultural mantenido por generaciones, lo cual tiene diversas implicancias en las formas de comprender las dinámicas del territorio.

Cabe señalar que estos escritos son producto del trabajo de campo de una investigación emprendida hace tres años, en la cual se realizaron entrevistas y encuestas a actores claves, se aplicó el método Delphi a expertos en estas temáticas y un largo proceso de observación que fue fundamental para comprender cómo se expresan estos fenómenos en el territorio.

revista invi № 82 / Noviembre 2014 / Volumen № 29: 189-216 191 


\section{Territorio, paisaje, paisaje agrario y ruralidad}

Históricamente se ha comprendido al territorio como la suma de recursos naturales. Sin embargo,

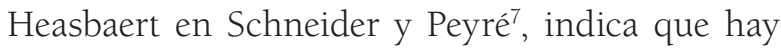
tres dimensiones para percibir y conceptualizar el territorio: "la política o jurídico-política, en que el territorio es considerado como espacio controlado por un determinado poder, a veces relativo al poder del Estado (institucional); la cultural o simbólico-cultural, donde el territorio es visto como un producto de la apropiación simbólica de una colectividad; y la económica, en que el territorio sirve como fuente de recursos (dimensión espacial de las relaciones económicas)", es decir, en el territorio se reconocen huellas visibles e invisibles, personales y colectivas, donde surgen identidades, pertenencias, historias y los vestigios del contexto económico, social, cultural y tecnológico ${ }^{8}$.

De este modo, hoy el concepto constituye una manifestación más dinámica del "espacio social como reproductor de las acciones de los actores sociales" 9 . A través de las acciones sociales se entrecruzan de manera simultánea diversos procesos sociales que originan el territorio, lo cual le otorga identidad al espacio y le permite asumir diversas escalas y

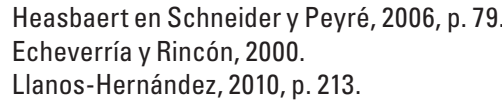

Llanos-Hernández, 2010, p. 213.

manifestaciones, desde pequeños territorios hasta territorios-red ${ }^{10}$.

Según lo planteado por Echeverri, el territorio es una construcción histórica de "apropiación de un espacio dotado de recursos naturales que forman ecosistemas singulares que determinan formas particulares de aprovechamiento de estructuras económico productivas"11 donde se cimienta la base para la construcción de redes sociodemográficas e institucionales y economías particulares. En este proceso de construcción del territorio se establecen tradiciones y cultura, las cuales son el soporte de la identidad y territorialidad, y es en este espacio en el que interactúan dimensiones de la vida social y se define un entorno económico.

Para Marull et al., el territorio es comprendido como un sistema complejo, por lo cual se sitúa desde un modelo ecosistémico para estudiarlo. Para este modelo, el paisaje es un "sistema organizado en niveles jerárquicos de complejidad que dependerían de su escala espacio-temporal"12. Tan pronto el hombre marca su presencia en el territorio y adecua su entorno natural para habitarlo, lo cualifica y condiciona, y a su vez éste afecta y transforma a quienes lo habitan, constituyéndose como una parte vital del ser humano ${ }^{13}$. En esta interacción entre sujeto y naturaleza se constituyen los paisajes culturales.

10 Schneidery Peyré 2006

11 Echeverri, 2011, p. 14

12 Marull, Pino, Tello, y Mallarach, 2006, p. 106

13 Echeverría y Rincón, op. cit.; Rolón y Rotondaro, 2011. 
Según su traducción, el concepto paisaje desde sus orígenes ha sido relacionado con la porción de terreno centrada en la vida y el cultivo, lo cual atañe a la noción de lugar y país, aludiendo a que la palabra se aproxima al "aspecto o síntesis de un territorio", que se basa en el análisis de su construcción histórica ${ }^{14}$. Si nos atenemos al pensamiento de Varela ${ }^{15}$, el paisaje se define como el entorno que un individuo utiliza y percibe, es decir, una interfaz entre un organismo y su entorno. El ser humano actúa sobre la base de su percepción e interpretación particular del paisaje, lo cual le otorga un carácter subjetivo $^{16}$. Dicho de otro modo, existen tantos paisajes como individuos y, sin embargo, el paisaje también es resultante de procesos evolutivos naturales, por lo cual implica también una connotación objetiva.

Así, el paisaje deja de ser natural cuando el ser humano hace cualquier intervención en él, y es por ello que Maderuelo ${ }^{17}$ señala que el concepto de paisaje supera la conjunción de elementos físicos y se va configurando como un espacio utilizado para la contemplación, y es por lo mismo que para la realización de esta acción se hace necesaria la presencia de un observador, en la medida que transmite actividad humana material y mental ${ }^{18}$.

14 Prada, 2005.

15 Varela, 1999

16 Tesser, 2000.

17 Maderuelo, 2005.

18 Orejas, 1995.
Este ejercicio de contemplación supone que el observador atribuya ciertos sentimientos vinculados con el paisaje observado, los que variarán según los fenómenos culturales a los que está expuesto el mismo. Es por ello que el paisaje como idea se construye en la relación entre medio físico y lo subjetivo e interpretativo en tanto constructo cultural, puesto que, "solo hay paisaje cuando hay interpretación y ésta es siempre subjetiva, reservada y poética, y si se quiere, estética"19. Sin embargo, la idea de paisaje no es sólo el objeto ni quién lo contempla, sino lo que se ve, por lo que requiere un adiestramiento para contemplar que permita distinguir los elementos característicos y estructurales que lo componen, generando así un disfrute de la imagen de un territorio.

Sin embargo, el paisaje también puede ser analizado desde otros puntos de vista. Para la sociología el paisaje son expresiones culturales de "los modos y formas variables según tiempos y las sociedades, las relaciones que el hombre establece con el medio que los rodea"20.

En esta línea, cabe señalar que se pondrá especial interés en el paisaje cultural, en el que pueden existir tres tipos complementarios de tendencias o

\footnotetext{
19 Maderuelo, op. cit., p. 35

20 Tesser, 2000, p. 21.
} 
determinantes: en los que se impone la producción de bienes y/o servicios (cultural económico); en aquellos en los cuales predominan las condiciones para el asentamiento y desarrollo de la vida humana (cultural social). O, simplemente, en los que predomina la naturaleza salvaje (cultural ecológico). De este modo, una aproximación que aporta a la discusión, es la comprensión del paisaje y sus elementos como una articulación producto de procesos económicos y ecológicos, ya que "toda forma de supervivencia humana involucra la adecuación y adaptación de la naturaleza para crear hábitat. En otras palabras el hombre se convierte en un agente trasformador del medio físico, y todo lo que existe pasa a transformarse de un elemento de la naturaleza a un recurso, en la medida en que este adquiere 'valor' para la formación del hábitat y por tanto para su propio mantenimiento y beneficio"21. Así, el paisaje puede ser utilizado y modelado para producir comida, abrigo, mantenimiento biológico, el mantenimiento social, cultural, entre otros, según los diferentes modos de vida. Es aquí que el paisaje se presenta como una oportunidad de satisfacción de necesidades, donde lo existente ha sido modificado y transformado para crear hábitat, ya que el ser humano "moldea a la naturaleza de acuerdo a sus propios requerimientos de manera que gradualmente

21 Raposo, 2006, p. 9.

194 revista invi № 82 / Noviembre 2014 / Volumen № 29: 189-216 la transforma en paisaje"22. En síntesis, el paisaje es una construcción social y cultural adscrita a un espacio material y físico ${ }^{23}$.

Otra forma de comprender el paisaje cultural es desde la óptica del patrimonio, ya que se entiende como las transformaciones que el ser humano hace sobre la naturaleza integrando los recursos patrimoniales a un territorio, donde lo material depende de lo inmaterial y se valora las distintas manifestaciones y expresiones culturales de los grupos que lo comparten, extendiéndose la relación entre patrimonio natural y cultural ${ }^{24}$. Así también surge la idea del paisaje-memoria, el cual es un espacio donde se materializa la historia del hombre, de modo tal que el paisaje es considerado como "un archivo de las técnicas y prácticas de los sistemas sociales, politicos, culturales y tradiciones pretéritas" ${ }^{25}$

Es así que el paisaje, tanto natural como humano y cultural, realiza una construcción particular del territorio donde se expresan dinámicas, interacciones e identidades distintas, las que ciertamente tienen una expresión especial en el hábitat rural. En el contexto de las azudas de Larmahue se puede observar cómo su paisaje, que en parte está protegido por sus dotes patrimoniales, define estas dinámicas e interacciones que allí ocurren,

\footnotetext{
22 Gastó, Vieli y Vera, 2006, p. 30.

23 Nogué y San Eugenio Vela, 2011.

24 Beltrán, 2009.

25 Tesser, op. cit.
} 
sirviendo así como paisaje-recurso en tanto objeto de consumo turístico, de conservación y de gestión para aportar al desarrollo económico.

\section{Hábitat rural y agricultura}

El hábitat, definido desde una concepción ecológica, es la especificación territorial de una comunidad, la que se caracteriza por sus condiciones ambientales de un lugar concreto ${ }^{26}$. En él se contiene la vida humana, rompiendo con la dicotomía ser humano-naturaleza que lo alberga, ya que integra lo simbólico, emocional y político desde las relaciones del sujeto con otros en diversos escenarios territoriales ${ }^{27}$.

Es en el territorio rural cuando este proceso histórico de construcción social se sustenta mayoritariamente en los recursos naturales de los cuales depende estructuralmente, porque de ellos se basa una economía sustentada de la oferta ambiental. Esta definición tensiona la dicotomía urbano-rural porque establece una "nueva forma de relación de densidades, incluyendo concentraciones poblacionales que forman parte de territorios rurales, de centros urbanos con funciones rurales, al tiempo que incluye todos los sectores económicos que tienen lugar en este tipo

26 Pérez Maldonado, 2000.

27 Echeverría, 2009. de territorios, más allá de las actividades agrícolas o de sus encadenamientos directos" 28

Como en todos los espacios habitados del planeta, desde sus inicios el espacio habitado en América Latina fue netamente rural, pero se comienza a modificar debido a la diversificación de actividades humanas no agrícolas, lo cual permite el surgimiento de las ciudades. Sin embargo, la industrialización de la ciudad aumenta la dependencia del campo para acceder a sus insumos, así como la ciudad depende de los productos agropecuarios. De este modo, los lugares rurales responden a un hábitat cultural que se basa en la explotación primaria de los recursos locales, y en la medida que los asentamientos aumentan de tamaño, se desarrollan actividades terciarias para responder a las necesidades de la población agrícola y de su entorno.

En este contexto se hace necesario poner especial atención en la agricultura. Ésta se comprende como el proceso de artificialización de la naturaleza ${ }^{29}$ que transforma lo natural en rural. Así, se simplifica entonces la organización natural de un ecosistema para ordenar sus componentes según las necesidades humanas.

El caso de la agricultura familiar de subsistencia -relacionada con el pequeño productor que tiene

28 Echeverri, op. cit., p. 15

29 Lawes, 1847; Gastó, Armijo y Nava 1984 
gran presencia en Larmahue-, es una dimensión que se considera independientemente de los sistemas políticos, económicos, socioculturales, o productivos, presentes en el sector agropecuario de los países latinoamericanos ${ }^{30}$. Sus características son las siguientes:

- Extensión del predio y tipo de cultivo: predio menor a 5 há. El tipo de cultivo es la chacra (cultivos variados en una pequeña extensión) y huertos.

- Utilización de mano de obra familiar: la explotación del predio depende directa y principalmente de la vinculación de la fuerza de trabajo familiar $^{31}$, sin perjuicio del empleo ocasional en otras actividades o de la contratación de mano de obra temporal.

- Lugar de la vivienda: un factor importante que permite acotar la identificación de la agricultura familiar es que el lugar en donde se desarrolla la actividad productiva coincida con el lugar de vivienda.

- Fuente de ingresos: generalmente no se cultiva para percibir ingresos, y cuando se comercializa lo producido, la proporción del ingreso es mínimo.

30 Acosta y Rodríguez, s.f

31 Echenique, 1988

196 revista invi № 82 / Noviembre 2014 / Volumen № 29: $189-216$
En el caso de la agricultura de exportación -relacionada con el concepto de empresario agrícola, actores muy influyentes el Larmahue-, es totalmente contraria a los planteamientos de una agricultura familiar de subsistencia, ya que explota una superficie muy superior a 5 Há, el tipo de cultivo generalmente obedece a viñas y parronales, utiliza mano de obra asalariada y gran parte del ingreso proviene de la comercialización en el exterior.

Al identificar el territorio con la agricultura y el espacio rural, se devela una estrecha relación con la complejidad conceptual del territorio, donde se pueden articular tres acepciones ${ }^{32}$ :

- Físico-natural: el territorio como proveedor de recursos y receptor de impactos.

- Sociocultural: el territorio como construcción humana y herencia compartida.

- Geográfica: el territorio como una integración de nodos (ciudades), redes (infraestructuras de comunicación) y superficies (entre la que los espacios de la agricultura ocupan una posición destacada, aunque en convivencia con otros usos).

En consecuencia, en el territorio rural la agricultura logra generar un paisaje cultural resultante de la actuación del hombre con o sin una intención

32 Silva, 2010, p. 20 
definida, generando en cada caso un paisaje diseñado o simplemente residual. Así entendido, hacer agricultura es producir bienes y servicios (económicos, sociales, patrimoniales, ambientales) que están vinculados con el territorio en el que se enmarcan. A pesar de que hay recursos calificados como "no comerciales", estos aportan a la activación económica de los territorios rurales, y de este modo también generan escenarios y paisajes ecológicamente sostenible y socialmente aceptable, donde sea posible una buena calidad de vida para el hombre. La actuación del hombre en un territorio rural puede generar, además del valor económico, efectos identitarios que radica en la conformación del paisaje cultural y patrimonial ${ }^{33}$

En el contexto de una agricultura de regadío, existe una estrecha relación entre los asentamientos humanos, territorio y ambiente, que desde el punto de vista de la producción, la ocupación, la población y las infraestructuras, tiene diversos impactos en la tradición alimentaria y, por consiguiente, en las prácticas agrarias y en la propia identidad cultural local ${ }^{34}$. Así, el agua es un factor esencial en la agricultura; la producción de cultivos está íntimamente ligada a la necesidad de agua dulce. Una vez que las plantas captan el agua en su biomasa, la devuelven a la atmósfera mediante la transpiración, proceso que beneficia las condiciones

33 Van Mansvelt y Stobbelaar, 1995; Silva, 2010. 34 Perelli, 2004 microclimáticas. Bien se sabe que la agricultura depende del clima y de las condiciones naturales; de hecho, las condiciones climáticas cambiantes producen desequilibrios entre las precipitaciones y las necesidades de los cultivos durante la vegetación, lo que provoca graves consecuencias para los rendimientos y para la calidad de los productos agrícolas, como las sequías, por ejemplo, fenómenos que aumentan la vulnerabilidad del sector agrícola ${ }^{35}$. De este modo, el agua es un componente importante en la relación actividad humana y medio ambiente natural, debido a que afecta directamente sobre las "condiciones biológicas, físicas, culturales, estéticas y políticas del hábitat"36. Así, las nuevas tecnologías que surgen para regularizar la disponibilidad de los recursos hídricos inciden en la distribución y expansión de nuevas tierras productivas, lo que le permite constituirse como uno de los principales agentes en la ordenación del territorio y en la transformación del paisaje cultural.

En el contexto de las azudas, la estrechez que existe entre el artilugio y las prácticas de la localidad son fundamentales. Esto porque permite observar cómo la existencia de una forma particular de regadío delimita las formas de desarrollar la actividad económica en la localidad, aspecto que es altamente valorado por sus habitantes.

35 INIA, 2009

36 Burmil et al, 1999 en Rolón y Rotondaro, 2011, p. 160. 


\section{Las ruedas de Larmahue}

En América, las azudas se han localizado preferentemente en México, Jamaica y Chile, siempre en territorios rurales. Hoy en día sólo se mantienen funcionando las de Chile.

Por lo anterior, lo que interesa exponer a continuación es una manifestación particular de la conformación de un territorio y un paisaje en contextos de ruralidad. En efecto, la investigación que sustenta esta comunicación trata sobre los efectos transformadores de la acción humana durante el último siglo en una zona campesina del centrosur de Chile, como lo es la comuna de Pichidegua, situada en la provincia de Cachapoal, en la región del Libertador General Bernardo O'Higgins, 120 kilómetros al sur de Santiago de Chile, y particularmente en su localidad de Larmahue que ocupa una superficie de $39 \mathrm{~km}^{2}$, correspondiente al 12\% del territorio comunal.

Lo relevante es que en la zona estudiada se ha producido una modificación significativa del territorio, originalmente con características de secano y que por efecto de la intervención de sus habitantes ha devenido en una zona con cualidades aptas para la agricultura. En este caso, la acción del hombre se expresa primeramente en la construcción del canal Almahue, que aprovecha las aguas del río Cachapoal y posteriormente -lo que resulta de central interés para esta investigación- la construcción de ruedas de regadío, denominadas azudas.

Efectivamente, las azudas son ruedas hidráulicas que para los árabes eran instrumentos fundamentales en el sistema de riego que sostenía sus campos y cultivos, considerando que se situaban en territorios áridos, mayoritariamente de secano. No hay certidumbre de su origen en Chile, pero se podría sostener que provienen del sistema de hacienda impuesto por los colonizadores hispanos, quienes heredaron las costumbres y modos de vida de la cultura islámica.

De este modo, el uso de las azudas tiene una importante presencia en la localidad de Larmahue, para cubrir parte del riego campesino. Se trata de un reducido grupo de ruedas de madera que giran conforme lo propone la escorrentía del canal Almahue. Es así que constituyen una muy eficiente respuesta a una de las necesidades primordiales del hombre: la provisión de agua de regadío para la agricultura.

Estas ruedas de agua se muestran como una secuencia de hitos dispuestos en un tramo del largo camino pavimentado que une el cruce del Puente Codao con San Vicente de Tagua Tagua, marginando las localidades rurales de Portezuelo de Larmahue, Vice-parroquia de Larmahue (La Católica) y Lo Argentina. Aunque en menor cantidad, también las hay en el Fundo San Roberto y en las localidades de Salto de Almahue y El Asta. En la 
FIGURA N ${ }^{\circ}$ : LOCALIZACIÓN DE AZUDAS EN LA COMUNA DE PICHIDEGUA

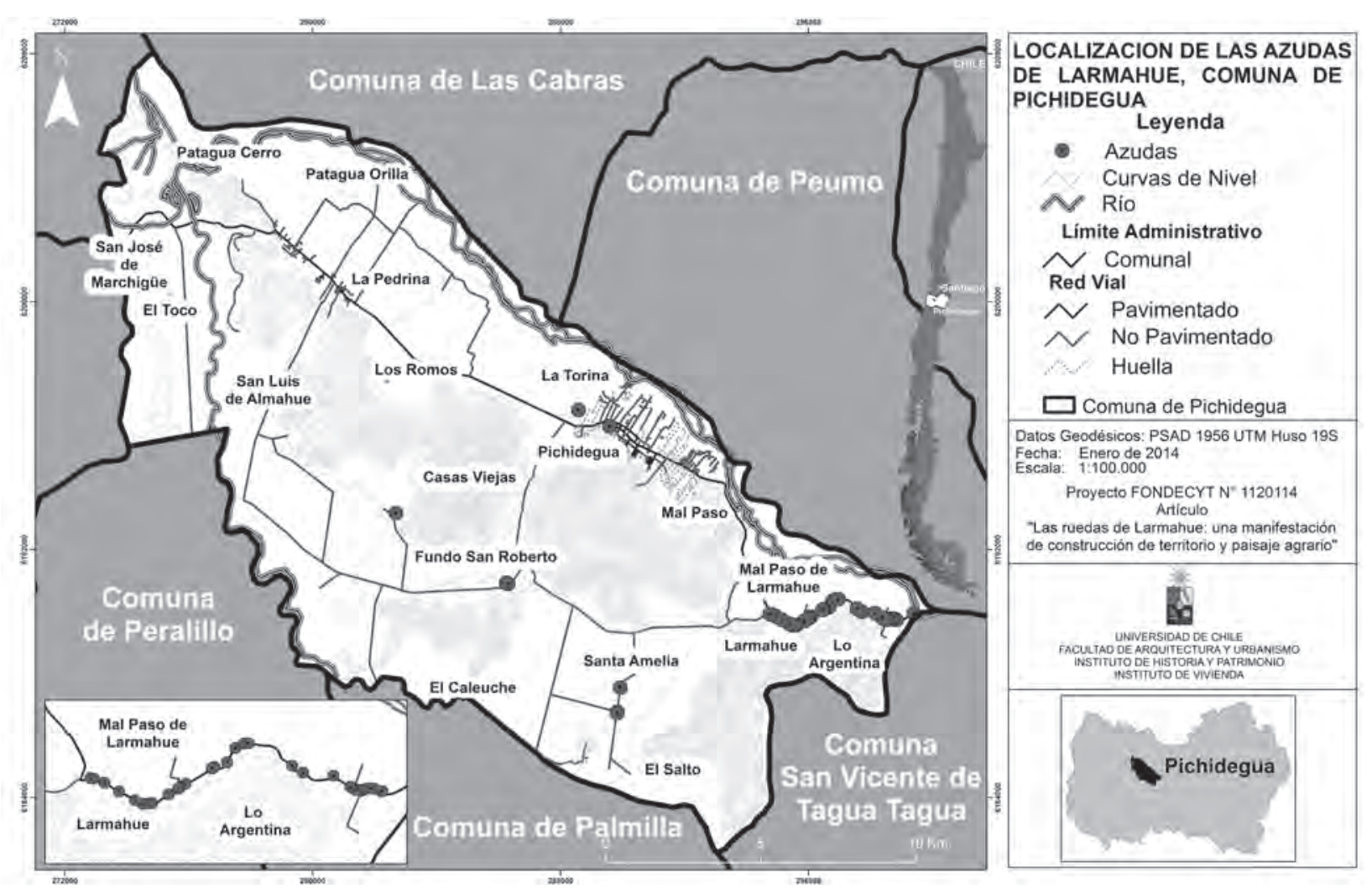

Fuente: Autores. 
Figura $\mathrm{N}^{\circ} 1$ se puede visualizar la localización de las azudas en la comuna de Pichidegua.

La mano del campesino es perceptible en el escenario pichideguano. La necesidad de capturar agua para el regadío en tierras de secano ha estimulado la creatividad artesanal. Producto de la inventiva son las azudas y su técnica asociada, frente a lo que Marull convendría que el paisaje cultural se deja antropizar sin que se adulteren sus atributos esenciales.

En efecto, el uso de las azudas nace de la necesidad de transportar agua de riego hasta terrenos cuyas cotas son más altas que las del canal que los podría abastecer. Su misión es, precisamente, elevar el agua, sorteando los problemas de pendiente que impone la topografía. Se presume que el modelo creado en esta región de Chile apela a los antecedentes que ofrecen las norias o ruedas de corriente incorporadas por los españoles a contar del siglo XVIII.

Actualmente no existe una fuente escrita que dé fe acerca de los orígenes del uso de las azudas en Chile, siendo por ello fundamental el testimonio oral de los antiguos habitantes de Pichidegua. La coincidencia de esas declaraciones permite sostener, hoy día, que la construcción de la primera rueda en Larmahue se remonta a las primeras décadas del siglo XX. Los datos, sin embargo, no son enteramente comprobables: su construcción, atribuida a Celso Zamorano, ${ }^{37}$ respondió originalmente a la necesidad de obtener energía eléctrica. En segunda instancia, cuando la fuerza de la corriente del Canal Almahue se hizo insuficiente, Zamorano habría cambiado el destino de la rueda, orientándola a un uso agrícola. Se trataba, en suma, de mitigar los efectos adversos que derivan del ambiente secano, tan propio de los campos de Larmahue.

Se especula que el diseño de la primera rueda de agua de la zona -construida por el maestro carpintero Manuel Segundo Arriaza- es tributario de los bosquejos y descripciones de los libros que poseía Zamorano, la mayor parte de ellos referidos a las ruedas hidráulicas españolas.

La tradición oral revela que Zamorano, entusiasmado por la exitosa aplicación de su rueda a las tareas agrícolas, y no obstante su esmero por mantener en reserva su idea, su artilugio fue reproducido por los agricultores vecinos. Se multiplicaron, entonces, sucesivamente, las ruedas a la vera del Canal Almahue, comenzando por el sector de Lo Argentina, siguiendo por Viceparroquia y Portezuelo, hasta llegar, finalmente, a las pilastras de Almahue, lugar de término del canal en esa época.

37 Celso Zamorano dedicó gran parte de su vida a la construcción de azudas y se le atribuye la firma de los estatutos de riego del Canal de Almahue y la personalidad jurídica correspondiente. 
Tal fue el prestigio que alcanzaron las ruedas de agua (o azudas) en Larmahue, que no tardaron en ser replicadas -en menor escala, eso sí- en otros sectores más o menos próximos. Es el caso del fundo San Roberto, donde se construyeron, entre 1934 y 1936, dos imponentes ruedas.

Es así como a mediados del siglo XX, en algún momento se afirma que hubo 80 ruedas, ${ }^{38}$ en 1988 había 30 en funcionamiento y a ellas se añadieron hasta 10 más. A finales de la década de 1990 se hablaba de 40 ruedas. ${ }^{39}$ En el año $2012^{40}$ se catastraron 44 azudas, distribuidas dentro de la comuna de Pichidegua, lo que demuestra su pervivencia.

A pesar de las transformaciones propias de la modernización del campo, las ruedas no han dejado de ser objeto de curiosidad y admiración de viajeros y visitantes. En poder de familias patriarcales, las ruedas han superado varias generaciones, manteniéndose hasta la actualidad y la tecnología que requieren para mantenerse vivas es patrimonio de sus propietarios. Algunas de las familias responsables de su supervivencia: Barrios, Yáñez, Toro, Villaseca, Lucero, Zamorano, Cabezas, Leyton y Huerta, en los sectores Viceparroquia y Portezuelo; Fuentes, Romo, Arriaza, Mateluna y Huerta, en el sector de Lo Argentina.

38 Guarda, 1988, p. 31.

39 De las Casas Gómez, 2007, p. 122.

40 Sahady, Bravo y Quilodrán, 2012.
Con el tiempo las ruedas se convirtieron en el obligado referente del paisaje cultural y de la actividad agraria de Larmahue, cualificada por el secano costero de la zona. Corría el año 1998 cuando se consiguió la declaratoria de "Monumento Histórico" de las azudas de Larmahue. El Consejo de Monumentos Nacionales la concedió -previo consentimiento de sus propietarios-, por medio del Decreto $N^{\circ} 830$, a 17 de las 37 ruedas registradas hasta entonces.

Pese al compromiso contraído por parte de sus dueños y la propia Municipalidad de Pichidegua, las ruedas sufrieron un deterioro progresivo. No fue suficiente el apoyo del Consejo de Monumentos Nacionales, que se esmeró en contribuir con la madera necesaria para la manutención de las estructuras. Fue la propia autoridad municipal que consiguió incluir, en 2002, las mismas ruedas de Larmahue, en el listado del Patrimonio Mundial en Peligro de Extinción "World Monuments Watch". Finalmente, durante el año 2009, las ruedas de Larmahue obtuvieron el Sello Bicentenario.

Sin embargo, a pesar de tener un valor patrimonial, paisajístico y una fuerte raigambre campesina, estas ruedas han sido escasamente difundidas por los medios escritos y audiovisuales. 
A lo anterior, se suman los estragos del sismo del 27 de febrero de 2010, que se dejaron sentir en la estructura de varias de las azudas, trayendo consigo consecuencias de variado orden en la región: económicas, territoriales, culturales y, por extensión, efectos sobre el patrimonio tangible e intangible.

\section{Azudas: el paisaje construido de Larmahue}

En el proceso de consolidación del territorio pichideguano se han ido instalando, de manera paulatina, algunas tradiciones y costumbres. En medio de este contexto, sin que aún resulten gravitantes en la identidad de la comuna, las azudas marcan una territorialidad diferenciada, un marco social y un entorno económico definido.

En relación al párrafo anterior desde el punto de vista de la propiedad rural, la comuna de Pichidegua se puede dividir en tres grupos de propietarios agrícolas: pequeños propietarios, medianos propietarios y empresarios agrícolas, lo cual influye directamente en la definición de límites respecto de los actores que allí confluyen, permitiendo establecer estas grandes diferencias identitarias que se ven expresadas en el entorno físico y en las

202 revista invi № 82 / Noviembre 2014 / Volumen № 29: 189-216 acciones cotidianas y de subsistencia, según el rol que ocupan en el territorio. En la figura nro. 2 se puede identificar territorialmente la división de la propiedad agrícola de Pichidegua.

Esta división socioeconómica es correspondiente, curiosamente, con la realidad geográfica: por la comuna cruza un cordón montañoso, compuesto por los cerros que van desde El Toco hasta Los Guindos. Los accidentes orográficos definen, en buena medida, los diversos escenarios agrícolas sobre los que se asientan los cultivos. Tres son los sectores resultantes de la interposición del cordón montañoso, enfatizados progresivamente en el tiempo:

- El sector que corresponde a los pequeños propietarios de terreno de secano en Larmahue, compuesto por las localidades de Lo Argentina, Vice Parroquia y Portezuelo.

- El sector de riego del antiguo Fundo Almahue, estructurado por las localidades de San Roberto, Salto de Almahue y El Asta, correspondientes a los empresarios agrícolas.

- El sector urbano y que comprende las localidades de Pichidegua y La Torina, asociado a medianos propietarios.

En el sector de secano de Larmahue, ${ }^{41}$ a lo largo del camino que une Pichidegua y San Vicente de

41 La toponimia de Larmahue, en lengua indígena, significa “lugar de arbustos". 
FIGURA N²: PROPIEDAD AGRÍCOLA DE LA COMUNA DE PICHIDEGUA

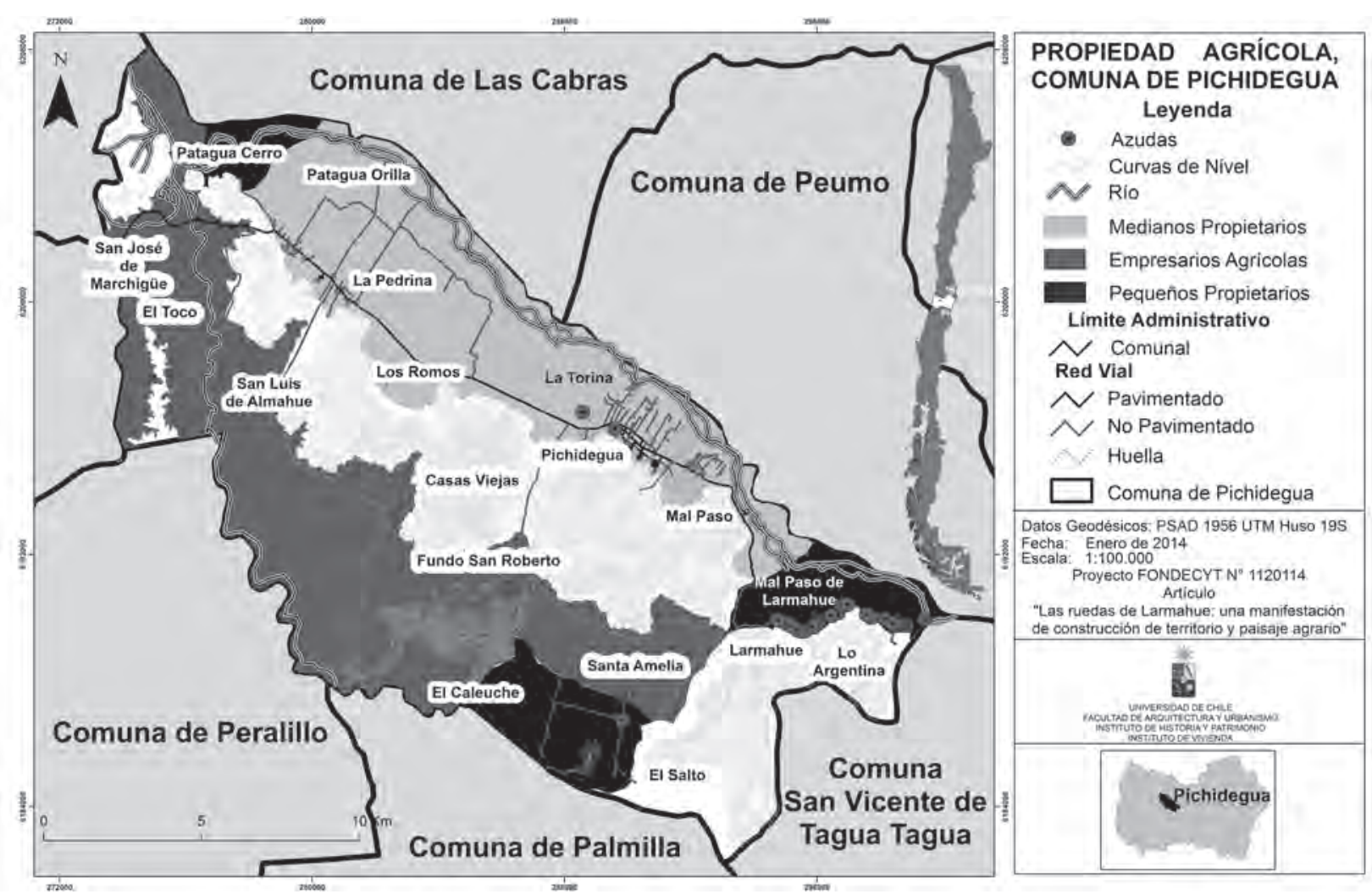

Fuente: Autores 


\section{FIGURA N 3 SECTOR LO ARGENTINA. PATIO INTERIOR EN CASA DE ADOBE DE PABELLÓN CONTINUO}

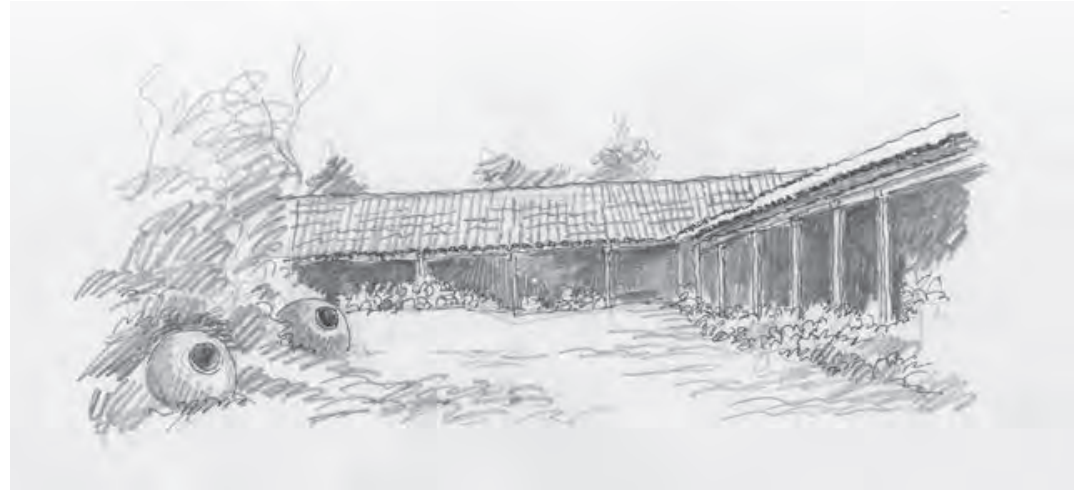

Fuente: Elaboración Propia, 2014

\section{FIGURA N 4 SECTOR VICEPARROQUIA. CASA DE ADOBE ASOCIADA A UNA AZUDA DE MADERA}

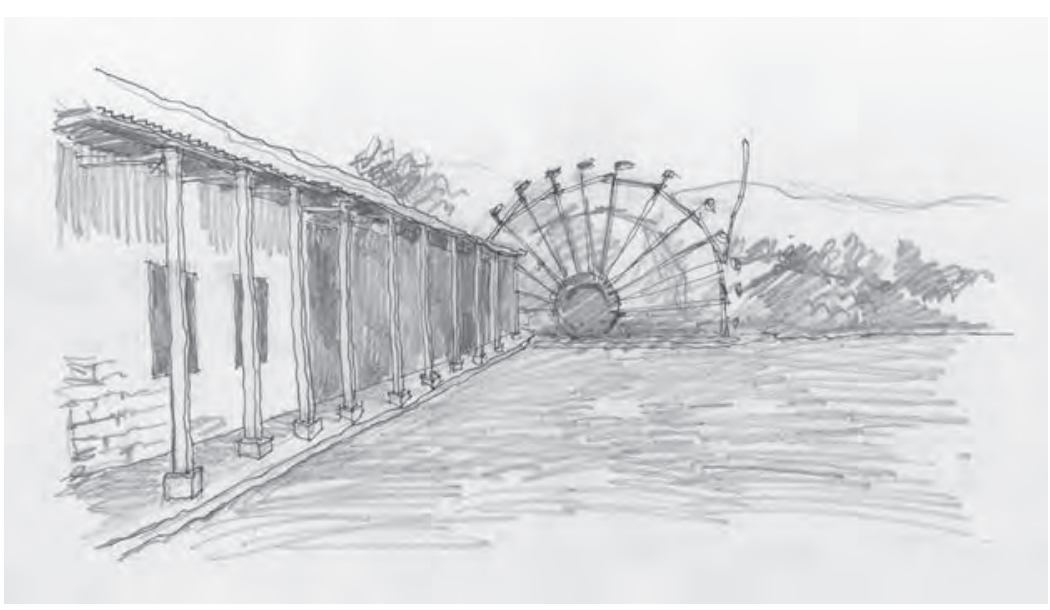

Fuente: Elaboración Propia, 2014

204 revista invi Nº 82 / Noviembre 2014 / Volumen N² 29: 189-216
ARTíCULO: Las ruedas de Larmahue: una manifestación de construcción de territorio y paisaje agrario / Jorge Larenas, Antonio Sahady, Marcelo Bravo, Carolina Quilodrán, 
Tagua-Tagua, se alternan las tradicionales casas de inquilinos con las casas de subsidio rural. La situación en el sector de Lo Argentina ${ }^{42}$ y Vice Parroquia ${ }^{43}$ es muy distinta: predominan las casas de adobe con corredores exteriores; en medio de ellas, algunas de albañilería reforzada. Abundan las pequeñas chacras, huertos y viveros de subsistencia familiar.

En Viceparroquia las ruedas de agua sirven, con un riego tecnificado, a huertos de tamaño mediano. Es el caso del Huerto "La Puntilla", donde destacan edificios y lugares de importancia cívica: la iglesia, el colegio, el cementerio y la cancha de fútbol.

Las viviendas de albañilería reforzada, producto del subsidio rural, predominan en Portezuelo. ${ }^{44}$ Sus propietarios trabajan en sectores agrícolas intensivos de huertos de frutales y cítricos. Es el caso del minifundio de San Ignacio.

A las viviendas de Viceparroquia se agrega el equipamiento comunitario: el Cuartel de Carabineros, la iglesia, la escuela, los locales comerciales de

42 La denominación de Lo Argentina proviene del sobrenombre que le dio a este lugar una profesora por lo lejano que quedaba de Pichidegua. Otra versión afirma que en este sector existía un pique minero que extraía materiales preciosos, como la plata 0 "argento". Antiguamente este sector era conocido como el "Rincón de los Zamorano".

43 El topónimo "Viceparroquia" se debe la iglesia de Larmahue. Por ello, también es conocida como "La Católica".

44 Este lugar se llama de este modo debido a la abreviatura del topónimo original de "Portezuelo de los Ahorcados", debido a que en este sector se ahorcaba a los bandidos y cuatreros del lugar. escala doméstica, la edilicia pública, el cementerio y dos monumentos (uno dedicado a San Francisco y, el otro, al bombero mártir Manuel Zamorano).

Tras la declaratoria de las azudas se han incorporado algunas áreas verdes, hoy día miradores escénicos, para que el visitante pueda disfrutar del marco natural y el funcionamiento de las ruedas. En las cercanías se han instalado quioscos de venta de artesanías y un apropiado mobiliario para acoger a los visitantes (asientos de concreto, tarimas de madera, letreros de troncos, señalética con materiales propios del lugar). Sauces y jardines de flores son un colorido complemento.

De los cuatro miradores solamente dos se han conservado y siguen cumpliendo su rol: el mirador $\mathrm{N}^{\circ} 1$ ("Las Ruedas") y el No 2 ("Viceparroquia"), emplazados en Lo Argentina y Viceparroquia. El Mirador No 3 ("Don Celso") 45 y el No 4 ("Zamorano") -ambos emplazados en Viceparroquia- han desaparecido: a la nula prevención se sumó el rigor del terremoto de 2010.

45 Este mirador lleva este nombre en honor a Celso Zamorano, constructor de la primera rueda de Larmahue.

revista invi Nº 82 / Noviembre 2014 / Volumen № 29: 189-216 205 
Las azudas de este sector rural se caracterizan por un diseño rústico, a la manera de una telaraña. El diámetro de cada rueda, por lo general, no supera los 10 metros. El material predominante es el roble pellín, no sólo en sus elementos estructurales, sino también en los accesorios. La vida útil de una rueda de agua oscila entre los 7 y los 10 años, siendo aconsejable, en consecuencia, que las operaciones restaurativas se hagan, por lo menos, cada 5 años. Una gran ventaja la constituye el que las ruedas estén conformadas por piezas independientes entre sí: favorece el desarme y la reposición de las partes.

En la zona de los empresarios agrícolas, como en el antiguo Fundo Almahue, ${ }^{46}$ se produce la agricultura de riego. Allí confluyen las localidades del fundo San Roberto ${ }^{47}$, Salto de Almahue ${ }^{48}$ y El Asta. ${ }^{49}$ El paisaje agrícola del Fundo San Roberto presenta claros indicios industriales, lo que se refleja en una enorme rueda de agua, elaborada en madera y hierro, con la que se riegan 30 hectáreas de viñedos cuya producción está destinada a un mercado exterior. El conjunto, que incluye una imponente casa patronal, se completa con las construcciones asociadas a las viñas y parronales que se extienden a través de las faldas de los cerros: bodegas y oficinas de arquitectura de reciente ejecución.

En la localidad de El Asta, el paisaje está en función del pequeño canal que pone en movimiento la rueda y permite el riego de un minifundio de frutales y viñedos que se extienden hasta trepar los cerros del entorno.

En el caso de Salto de Almahue se aprecia un paisaje algo más antropizado, heredado del antiguo Latifundio de Santa Amelia. Próximos a la casa patronal se encuentran las pesebreras, las bodegas y un silo cuya forma se asimila a una torre defensiva. Destaca el color blanco del conjunto -los muros de adobe enlucidos con pintura a la cal-, contrastado con el tono rojizo de los tejados de arcilla.

Muchas de las casas de los inquilinos fueron destruidas por el último terremoto y han sido abandonadas. No es raro que algunas de ellas fueran objeto de transformación: el adobe ha dado paso al ladrillo y a la madera; y, en la cubierta, la teja al fierro galvanizado.

46 El topónimo "Almahue" significa "lugar de almas".

47 Esta localidad lleva su nombre por el hacendado Roberto Lyon Santa María.

48 Este poblado posee esta toponimia por el salto de agua próximo, que lo abastecía.

49 Esta localidad debe su nombre a la forma de asta de buey que tenía un antiguo potrero de la familia Lyon, representado en los planos de 1926. 


\section{FIGURA N 5 SECTOR SALTO DE ALMAHUE. MÁS OUE UN ROL DE RIEGO AGRíCOLA, LAS AZUDAS CUMPLEN UNA FUNCIÓN ORNAMENTAL EN LA CASA PATRIMONIAL}

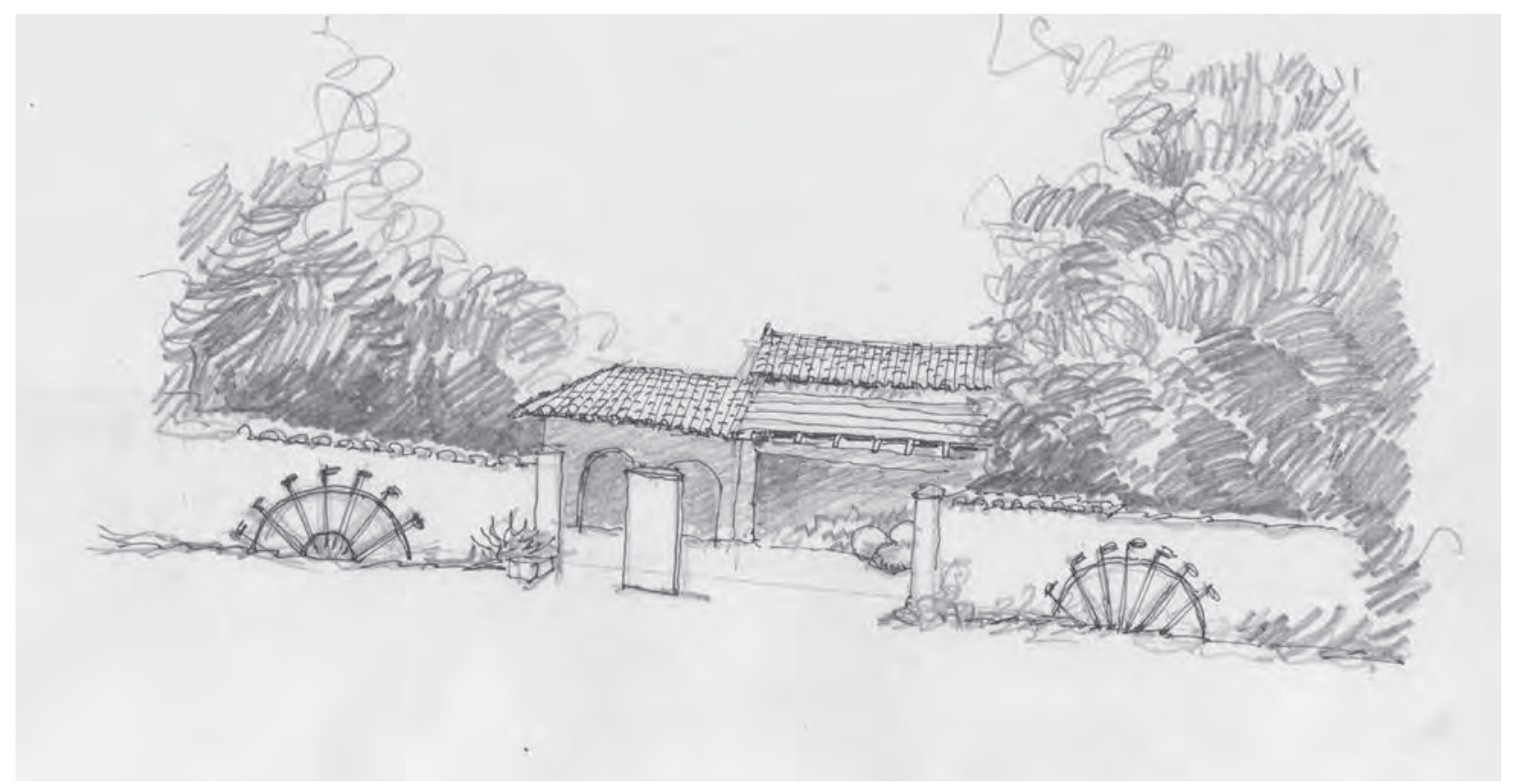

Fuente: Elaboración Propia, 2014

En la zona de San Roberto y El Asta existen sendas ruedas, muy antiguas, una por cada localidad. Se caracterizan por su gran tamaño (20 y 8 metros, respectivamente). De estructura mixta - metal y madera-, a diferencia de las ruedas de Larmahue, cuentan con tensores de acero para absorber los esfuerzos de los rayos que divergen desde el eje.

La técnica moderna consiste en conducir el agua que elevan las azudas a través de las cañerías subterráneas hasta tranques o piscinas de acumulación. 
Y luego, por medio de bombas hidráulicas llevarla hasta los campos de cultivos industriales e intensivos (viñas, paltos, cítricos y nectarinos, mayoritariamente) para practicar un sistema de riego por goteo o microaspersión.

Las ruedas de agua de Salto de Almahue, por su parte, tienen un sentido ornamental antes que de riego. Son, por lo mismo, pequeñas: cada una de las cuatro ruedas de madera no supera el metro y medio de diámetro. Se emplazan en la entrada de la casa patronal de Santa Amelia ${ }^{50}$ y a lo largo de una pequeña acequia próxima a ella.

La localidad de La Torina, ${ }^{51}$ por último, corresponde a un paisaje rural recientemente urbanizado: dispone, en la actualidad, de alumbrado eléctrico, agua potable y alcantarillado. Las tradicionales viviendas de adobe y tejas, tan propias del Valle Central, han sido reemplazadas por viviendas de albañilería reforzada y cubierta de fierro galvanizado, producto de los subsidios de vivienda rural a los que los habitantes han optado.

La rueda de agua local no ha escapado de estas tentaciones contemporáneas puesto que su diseño, inspirado en las azudas de Larmahue, resulta ser un producto híbrido que se vale de materiales reciclados (listones de diferentes maderas y bidones

50 Este topónimo proviene del nombre de la propietaria, Amelia Lynch.

51 La Torina fue propiedad del Conde de la Conquista Mateo de Toro y Zambrano. Eso explica su toponimia. recortados a modo de capachos), alcanzando poco más de un metro de diámetro, suficiente para cumplir con su modesta función, cual es el riego del pequeño jardín de una vivienda, cuyo patrón se aleja del tradicional de la zona.

Cabe señalar, por último, que como artefacto cultural, las azudas pueden ser consideradas un agente transformador del medio natural y productivo en las localidades en que se emplazan. De allí que el valor que las ruedas de agua tienen para sus propietarios está en directa relación con su hábitat, con el efecto social que irradian y, por cierto, con el beneficio económico que implica su actividad en el territorio.

\section{Azudas para la construcción de un hábitat rural}

Los postulados de Heasbaert ${ }^{52}$ aparecen nítidamente materializados en la realidad larmahuina: en ese paisaje que acoge a las azudas es posible advertir las diversas escalas espaciales y temporales, en las que concurren vestigios históricos, realidad social, tecnología sustentable, contexto económico. Variadas son, por lo tanto, las implicancias que

52 Heasbaert en Schneider y Peyré, op. cit. 
las azudas tienen en relación con el lugar al que pertenecen. He aquí algunas de ellas:

En el ámbito económico, las azudas permitieron que los campesinos de menores recursos pudieran generar, en pleno terreno de secano -o de rulo-, algunos paños cultivables en las proximidades de los canales de Almahue y de Madre Acequia y Protectora 1 , extensibles hasta los faldeos de los cerros pichideguanos. Se alcanzó, en algunos casos, a triplicar la superficie de cultivo. Este prodigio agrícola lo explica la presencia de las ruedas de agua, mediante las cuales se consigue capturar y elevar el agua desde los mencionados canales. Una vez que el recurso hídrico estuvo disponible, se aplicó, para el riego, en una primera etapa, la técnica tradicional de manga. Posteriormente, se introdujeron otras técnicas de riego: el goteo y la microaspersión.

Su gravitación en el campo del turismo local es también evidente. Pocas piezas artesanales alcanzan tan alto grado de singularidad -y rareza, podría decirse- como las azudas de Larmahue. Constituyen el más importante referente icónico dentro de paisaje de la comuna. Hasta la fecha, sin embargo, no ha habido un adecuado plan de gestión capaz de sustentar un programa turístico dentro de la comuna, aun cuando las condiciones que prodiga la naturaleza son inmejorables. No tuvo el éxito esperado, por ejemplo, la llamada "Ruta del Agua", toda vez que las autoridades locales no lograron involucrar decididamente a los empresarios locales y ni siquiera a la propia comunidad que, por no tener una relación directa con las azudas, prefiere desentenderse de ellas.

El despertar se produce sólo cuando se sabe de la existencia de fondos que promueven la actividad turística en la Región de O'Higgins. En efecto, existen diversas instituciones públicas que son proclives a la destinación de recursos a fines turísticos que redunden en el rescate de los valores patrimoniales propios del lugar. En este particular caso, se estimula la construcción de paradores turísticos, de miradores escénicos, la creación de una señalética apropiada y, sobre todo, la recuperación y manutención de los bienes que han sido víctimas del descuido o del franco abandono.

Tampoco deja de tener un efecto importante, en el clima de convivencia local, la relación que se establece entre canalistas y dueños de azudas. Los derechos de agua, los pagos de cuota de riego y la responsabilidad de cautelar el buen estado de las paredes del canal suelen ser periódicos motivos de fricción. Pero puede bastar un acontecimiento ajeno a la rutina cotidiana -el sismo de 2010, por ejemplo- para que los lugareños se sacudan de las malas prácticas y se muestren solidarios y unidos: en esa oportunidad los campesinos larmahuinos que eran dueños de azudas no pusieron obstáculos para compartirlas con aquellos vecinos que las 
perdieron temporal o definitivamente, conscientes de que el riego no se puede suspender.

Otro factor de unión local es "La fiesta de las Azudas", que la comunidad larmahuina celebra con comida y bailes típicos del campo de la zona central de Chile. Coincide este acontecimiento con la apertura de las compuertas del Canal Almahue, marcando el inicio de la temporada de siembras en Larmahue, San Roberto y Santa Amelia.

Finalmente, en el campo de la legislación, es preciso evidenciar las limitaciones de la Ley de Monumentos Nacionales: aun cuando un bien alcanza la categoría de Monumento Histórico, no percibe, por ese concepto, beneficio ni incentivo económico alguno. Esa nominación tampoco le cubre de eventos catastróficos. En la misma indefensión se encuentra el amplio espectro de manifestaciones de la cultura campesina, entre las que se cuentan las terrazas de cultivos y acueductos incas, en el Norte Grande: los Sistemas de Salinas en Cahuil y Paredones; los Molinos de Pañul y Rodelillo (VI Región), los Molinos heredados de la Colonización Alemana; los Molinos de Agua y Corrales de Pesca en la provincia de Chiloé. Y, desde luego, las azudas de Larmahue.

\section{Azudas: identidad pichideguana}

La percepción que los habitantes de Pichidegua tienen respecto de las azudas varía según sea la localidad específica en la que se emplazan. Una razón importante para justificar este efecto se encuentra en la diversidad orográfica del territorio, que trae como consecuencia distintas respuestas constructivas y diferentes usos del espacio conforme sean los recursos naturales disponibles. El resultado final se manifiesta en ecosistemas rurales particulares, que se identifican entre sí por sus estructuras económico productivas. Lo anterior, se demuestra en los resultados de la aplicación de una encuesta a 100 habitantes de la comuna, que dejan en claro que las azudas son mucho mejor valoradas por quienes pertenecen a aquellas localidades que cuentan con esos artilugios, sobre todo porque suelen ser usuarios de ellos. Esas localidades son Larmahue (Viceparroquia y Portezuelo) y Lo Argentina. En general, la percepción positiva va disminuyendo conforme los encuestados se alejan de la localidad de Larmahue; hay una excepción, sin embargo: los habitantes de Patagua Cerro. Este 


\section{FIGURA N 6: GRADO DE RELEVANCIA DE LAS AZUDAS PARA LOS HABITANTES DE PICHIDEGUA}

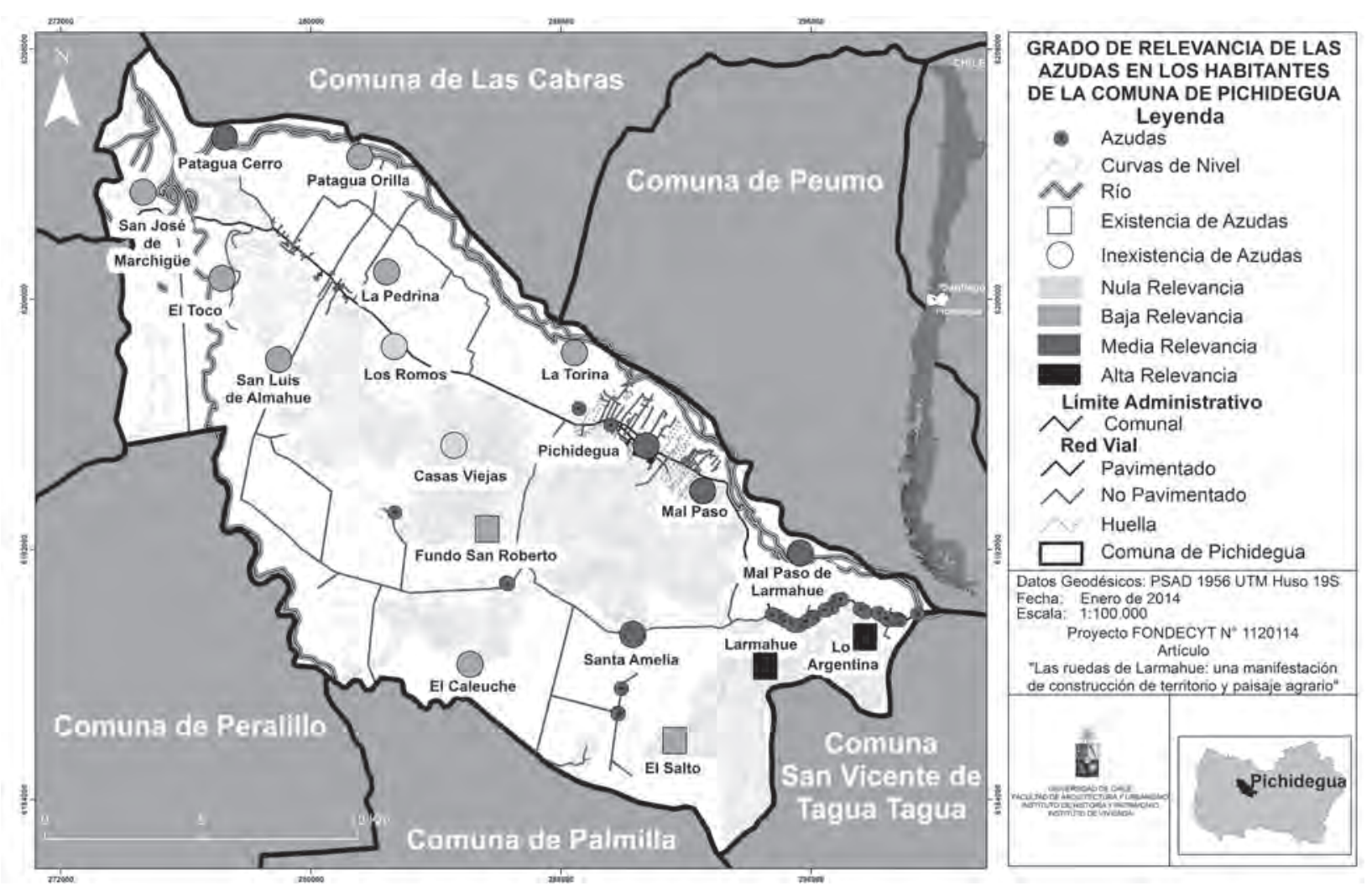

ARTÍCULO: Las ruedas de Larmahue: una manifestación de construcción de territorio y 
hecho se explica porque sus habitantes son, mayoritariamente, descendientes de larmahuinos. Lo anterior se puede ver expresado en la Figura $\mathrm{N}^{\circ} 6$.

Curiosamente, otras localidades que cuentan con azudas en sus territorios -San Roberto, El Asta y Salto de Almahue-, tienen una baja valorización. Se conjetura que el resultado, en este caso, es directamente dependiente del destino de la única azuda del lugar: se utiliza para el riego, en suelo fértil, de viñedos que pertenecen a una acaudalada familia local. Contribuye a esta percepción el rol disociador que cumple el cordón montañoso que divide a la comuna de Pichidegua, constituyéndose en una suerte de biombo histórico, agrario, económico y social.

La identificación de las ruedas de agua con la localidad de Larmahue, reconocida en distintos ámbitos del quehacer cultural, tiene, sin embargo, un débil correlato en las manifestaciones locales. Una de ellas es el escudo municipal, en cuyo diseño las ruedas de agua son un motivo central. Por extensión, un logotipo con pequeñas variaciones es utilizado por instituciones locales ligadas al deporte y el folclor pichideguano.

El Delphi -recurso metodológico utilizado en la investigación de campo-, aplicado a actores y profesionales vinculados a la azudas de Larmahue, ha demostrado que las azudas son apreciadas, preferentemente, más que por sus propios habitantes,

212 revista invi № 82 / Noviembre 2014 / Volumen № 29: 189-216 por personas ajenas a la comuna de Pichidegua. Incide en esta apreciación la novedad que representa para los visitantes el espectáculo de las ruedas en movimiento y el efecto real que tienen en la agricultura local: un sistema silencioso, natural, generador de energía limpia y, además, depositario de una estética singular, nítidamente campesina. Todo ello, sustentado en una tecnología de bajo costo, que permite la subsistencia de una agricultura en suelos de secano.

La valorización patrimonial, paisajística y simbólica de las azudas es directamente proporcional con la interpretación subjetiva de las características sociales, culturales y económicas de quienes las observan y hacen usufructo de ellas. ${ }^{53}$ Se explica, entonces, que la percepción y la relevancia de las azudas, como icono patrimonial e imagen de un territorio y paisaje cultural representativo de una zona campesina de Chile, sean variadas y específicas.

Es oportuno hacer presente, al final, que como elemento patrimonial del paisaje, las azudas cumplen un rol integrador: se funden en ellas elementos materiales e inmateriales del paisaje cultural en que se insertan y son, al mismo tiempo, agentes transformadores del medio natural y humano, lo que se demuestra en las diversas manifestaciones y expresiones culturales de los grupos que las comparten. $^{54}$

53 Maderuelo, op. cit., p. 35

54 Beltrán C., 2009. 


\section{Conclusiones}

Todas las señales indican que las Ruedas de Agua de Larmahue poseen gran significancia dentro de su territorio, formando parte de un paisaje muy particular dentro de la comuna. Es efectivo, además, que este paisaje es una de las piedras angulares de la identidad campesina y del estilo de vida de sus habitantes. Concentradas en un territorio donde prima la gestión y la eficiencia para con el recurso hídrico, la toma de decisiones tiende a resultar problemática.

Es posible concluir que el territorio de riego de la localidad de Larmahue ha sido altamente impactado por la presencia del conjunto Ruedas/Azudas. Los impactos socio-territoriales provocados por el conjunto Ruedas de Larmahue son percibidos por sus habitantes y se traducen en la existencia del monumento en sectores donde no necesariamente existe una necesidad de riego, siendo ésta la tónica que durante años ha ido configurando un singular paisaje cultural agrario, único en el país y en el mundo.

Los conflictos en esta zona no se relacionan precisamente con la existencia del monumento, sino con las falencias del instrumento que los protege, la Ley 17.288, alcanzando de manera inevitable repercusiones en la orgánica del canal de riego, en la comunidad y en la injerencia del gobierno a nivel local.
A través del presente estudio es posible concluir, además, que la importancia territorial del Monumento Histórico Nacional Ruedas de Larmahue va más allá de los límites definidos en el área de estudio, constituyendo el emblema de la comuna de Pichidegua y de cuanto evento social se realiza. El análisis socio-territorial arrojó datos al respecto, y para los habitantes de Larmahue, forman parte irremplazable de un paisaje cultural por ellos construido y del cual no están dispuestos a prescindir.

Por lo tanto, se considera necesario que el gobierno local se involucre completamente en la puesta en valor y posterior manejo del sistema de riego que incluye las azudas como pieza esencial, abordándolo desde una perspectiva integrada, no sólo del punto de vista de lo estético y arquitectónico, sino que incluyendo en la toma de decisiones a todos los actores, tanto a nivel de riego como de monumento. Incorporar en el Canal Almahue los primeros niveles de una gestión integrada de recurso hídrico puede ser la solución a una futura toma de decisiones que aseguren la sustentabilidad del territorio de riego en todos sus ámbitos.

\section{Bibliografía}

ACOSTA, Luis Alejandro y RODRíguEZ, Marcos Sebastián. En busca de la agricultura familiar en América Latina. [En línea]. s.f. Disponible en: http://www.agrotecnicounne.com.ar/biblioteca/ bibliografia-introduccion-a-las-ciencias-agrarias/

revista invi No 82 / Noviembre 2014 / Volumen N² 29: 189-216 213 
En_busca_de_la_agricultura_familiar_en_ LA.pdf.

BELTRÁN, Constanza. El patrimonio y los paisajes culturales, nuevos desafíos en su definición y manejo en rutas y paisajes culturales. Apuntes. Revista de estudios sobre patrimonio cultural. 22(1): 4-5, 2009. Pontificia Universidad Javeriana. ISSN 1657-9763.

DE LAS CASAS GÓMEZ, Antonio. Las ruedas de Larmahue: pervivencia en Chile de un sistema hidráulico español. En: ARENILLAS PARRA, Miguel, coord.; SEGURA GRAÍÑO, Cristina, coord; BUENO HERNÁNDEZ, Francisco, coord. y HUERTA FERNÁNDEZ, Santiago, coord. Actas del Quinto Congreso Nacional de Historia de la Construcción, Burgos, 7-9 junio 2007. España, Instituto Juan de Herrera, Ministerio de Fomento, Centro de Estudios y Experimentación de Obras Públicas, CEDEX. 2007. ISBN 978-84-7790-4465. p. 205-216.

ECHENIQUE, J. Topologías de productores agrícolas y políticas diferenciales. AGRARIA-FAO, Santiago de Chile, 1988

ECHEVERRI, Rafael. Reflexiones sobre lo rural: economía rural, economía de territorios. [En línea]. En DIRVEN, Martine. Hacia una nueva definición de rural con fines estadísticos en América Latina. Santiago, CEPAL. 2011. [Consulta: abril de 2013]. Disponible en: http://www.iadb.org/intal/intalcdi/PE/2011/08534.pdf.

ECHEVERRíA, María Clara. Hábitat: concepto, campo y trama de vida. En: ECHEVERRÍA, María Clara et al. ¿Qué es el hábitat? Preguntas por el hábitat. Medellín, Escuela del Hábitat CEHAP. 2009

ECHEVERRÍA, María Clara y RINCóN, Análida. Ciudad de territorialidades. Polémicas de Medellín. Medellín, CEHAP. 2000.

GASTÓ Juan; ARMIJO, Roberto y NAVA, Roberto. Bases heurísticas del diseño predial. Santiago, Chile, IISA, Pontificia Universidad Católica de Chile. 1984.

GASTÓ, Juan; VIELI, Lorena y VERA, Leonardo. De la Silva al Ager: paisaje cultural. Revista Agronomía y Forestal UC. 8(28): 29-33, 2006. ISSN 0717-4101.

GUARDA, Gabriel. Colchagua: arquitectura tradicional. Santiago, Chile, Ediciones Universidad Católica de Chile. 1988.

INIA. Nodo tecnológico de riego en el secano, Litueche. Región de O’Higgins. 2009.

LAWES, John Bennet. On agricultural chemistry. Journal of the Royal Agricultural Society of England. 8: 226-260, 1847.

LLANOS-HERNÁNDEZ, Luis. El concepto del territorio y la investigación en las ciencias sociales. [En línea]. Agricultura, sociedad y desarrollo. 7(3): 207-220, 2010. ISSN 1870-5472. [Consulta: junio 2013]. Disponible en: http://www.colpos.mx/ asyd/volumen7/numero3/asd-10-001.pdf

MADERUELO, Javier. La conciencia del lugar. En: MADERUELO, Javier. El paisaje: génesis de un concepto. Madrid, España, Abada. 2005. p. 
41-65. Lecturas, serie historia del arte y de la arquitectura.

_ La definición de paisaje. En: MADERUELO, Javier. El paisaje: génesis de un concepto. Madrid, España, Abada. 2005. p. 15-39. Lecturas, serie historia del arte y de la arquitectura.

MARULL, Joan; PINO, Joan; TELLO, Enric y MALLARACH, Josep M. Análisis estructural y funcional de la transformación del paisaje agrario en el Vallès durante los últimos 150 años (1853-2004): relaciones con el uso sostenible del territorio. [En línea]. Áreas. Revista Internacional de Ciencias Sociales. (25): 105-126, 2006. ISSN 1989-6190. [Consulta: mayo 2013]. Disponible en: http://revistas.um.es/areas/article/view/128031.

NOGUÉ, Joan y SAN EUGENIO VELA, Noé de La dimensión comunicativa del paisaje. Una propuesta teórica y aplicada. [En línea]. Revista de Geografía Norte Grande, (49): 25-43, 2011. ISSN 07183402. Disponible en: http://dx.doi.org/10.4067/ S0718-34022011000200003

OREJAS, Almudena Territorio, análisis territorial y arqueología del paisaje. [En línea]. Studia historica. Historia antigua. (13-14): 61-68, 1995-96. [Consulta: mayo 2013]. ISSN 0213-2052. Disponible en: http://campus.usal.es/ revistas_trabajo/index.php/0213-2052/article/viewFile/4166/4187

PERELLI, Augusto. Asentamientos humanos y paisajes agrarios. Barcelona, CIDOB, Icaria. 2004.

PÉREZ MALDONADO, Alberto. Calidad de vida y medio ambiente. En: CYTED-HABYTED. Memoria del II seminario y taller iberoamericano sobre vivienda rural y calidad de vida en los asentamientos rurales. Tomo I. San Luis de Potosí, México, Universidad Autónoma de San Luis de Potosí, Facultad del Hábitat, Universidad Autónoma del estado de Morelos. 2000. p. 143-158. ISBN 968-7674-83-0

PRADA, Esther Paisaje agrario: antropología de un territorio. Ciudad y territorio. Estudios Territoriales. (144): 343-372, 2005. ISSN 1133-4762.

RAPOSO, Gabriela. El paisaje y su imagen: de la construcción social al objeto de consumo. [En línea]. DU \& P: revista de diseño urbano y paisaje. 3(9), 2006. ISSN 0717-9758. Disponible en: http:// www.ucentral.cl/dup/9_paisaje_imagen.htm.

ROLÓN, Guillermo y ROTONDARO, Rodolfo. El agua de riego en la construcción del paisaje cultural en las zonas áridas del centro-oeste argentino: Un caso de estudio: Chañarmuyo, La Rioja. [En línea]. Revista de geografía Norte Grande. (48): 159177, 2011. ISSN 0718-3402. [Consulta: mayo 2013]. Disponible en: http://dx.doi.org/10.4067/ S0718-34022011000100009.

SAHADY, Antonio; BRAV0, Marcelo y QUILODRÁN, Carolina. Azudas de Larmahue: al rescate del recurso hídrico en medio de un terreno secano, en pleno valle del Cachapoal, Sexta Región. [En línea]. Revista AUS. (12): 18-21, 2012. ISSN 07187262. Disponible en: http://dx.doi.org/10.4206/ aus.2012.n12-05

SCHNEIDER, Sergio y PEYRÉ, Iván G. Territorio y enfoque territorial: de las referencias cognitivas a 
los aportes aplicados al análisis de los procesos sociales rurales En MANZANAL, Mabel, org.; NEIMAN, Guillermo, org. y LATTUADA Mario, org. Desarrollo rural: organizaciones, instituciones y territorio. Buenos Aires, Ciccus. 2006. p. 71-102.

SILVA PEREZ, Rocío. Multifuncionalidad agraria y territorio: Algunas reflexiones y propuestas de análisis. [En línea]. EURE. 36(109): 5-3, 2010. ISSN 0250-7161. [Consulta: mayo 2013]. Disponible en: http://dx.doi.org/10.4067/ S0250-71612010000300001

TESSER, Claudio. Algunas reflexiones sobre los significados del paisaje para la geografía. Revista de Geografía Norte Grande. (27):19-26, 2000. ISSN 0718-3402.

VAN MANSWELT, J.D., STOBBELAAR. Derk Jan. The landscape and nature production capacity of organic/sustainable types of agriculture. Wageningen, Wageningen Agricultural University, EE. UU. Department Ecological Agriculture. 1995. p. 247. Proceedings of the EU-concerted action AIR3 - CT93 - 1210.

VARELA, Francisco Javier. Invitation aux sciences cognitives. France, Editions du Seuil. 1999 